\title{
Reseña de Eugenio Coseriu: Competencia lingüística y criterios de corrección. Sevilla: Editorial Universidad de Sevilla (2019), 114 páginas. ISBN: 978-84-472- 2865-2
}

REVIEW OF EUGENIO COSERIU: COMPETENCIA LINGÜÍSTICA Y CRITERIOS DE CORRECCIÓN. SEVILLA: EDITORIAL UNIVERSIDAD DE SEVILLA (2019), 114 PÁGINAS. ISBN: 978-84-472-2865-2

\section{Adrià Pardo Llibrer}

Universitat de València

Para cualquier conocedor de la obra de Eugenio Coseriu, el libro Competencia lingüística y criterios de corrección -editado por los académicos chilenos Alfredo Matus Olivier y José Luis Samaniego Aldazábal- presenta una doble peculiaridad, si se quiere, tanto ecdóctica como anecdótica. Por una parte, el libro resulta de la recopilación, organización y edición de un curso homónimo, impartido por Coseriu en 1987, en la Pontificia Universidad Católica de Chile. Esta versión publicada del curso debía ir acompañada de una aplicación didáctica a cargo del lingüista uruguayo Juan Luis Piccardo, cuyo fallecimiento forzó su postergación hasta la fecha. Lo relevante aquí es que el presente texto había de ser el primer paso de un proyecto divulgativo no consumado: el acceso, por parte de maestros españoles e hispanoamericanos del idioma nacional, a algunas de las nociones básicas de la teoría lingüística estructural. El tiempo en barbecho del texto bien podría parecer excesivo; sin embargo, su contenido así lo exigía. He aquí lo anecdótico del libro: Coseriu aborda la cuestión de los criterios de corrección en relación no solo con la investigación y teorización lingüísticas (algo prolijamente expuesto en títulos como Teoría del lenguaje y lingüística general 1962, Madrid: Gredos; o Competencia lingüística. Elementos de la teoría del hablar 1992, Madrid: Gredos), sino también con consideraciones sociológicas y educativas tocantes al modelo de ejemplaridad de la lengua española en diferentes ámbitos y países.

Esto supone que estamos ante un libro no solo de lingüística; estamos, además, ante un libro con lingüística, interesado por la teoría misma y su repercusión en el mundo hispano. 
En este sentido, cabe preguntarse qué puede aportar esta obra, hasta cierto punto introductoria, al investigador; pero, también, qué puede aportar un planteamiento eminentemente teórico al docente. El libro se divide en cinco capítulos: los dos primeros podríamos agruparlos en un bloque, digamos, de contenidos abstractos; los dos siguientes, así como el tercero por su reducida extensión, en un segundo bloque de contenidos concretos. Así, los capítulos primero y segundo se encargan del concepto de corrección idiomática y su lugar dentro del saber lingüístico en general, respectivamente; los tres capítulos restantes tratan, en este orden, de la distinción entre corrección y ejemplaridad, los criterios que se asumen para estos dos conceptos y sus posibilidades en la enseñanza. En definitiva, un estado de la cuestión, el primer bloque, que fundamenta cómo abordar los problemas del segundo.

El primer capítulo problematiza el concepto de corrección. Si bien es cierto que el común de los hablantes -el hablante ingenuo- maneja una noción de corrección más o menos ortográfica y/o ortológica, la distinción de este concepto por parte de los lingüistas a menudo no es mucho más fina. A este respecto, Coseriu critica la existencia de una falsa oposición entre un modo de hablar purista y otro modo de hablar permisivo con aquello que hoy concebimos como incorrecciones. Ambos casos constituyen, como señala el autor, el mismo reduccionismo en dos direcciones: la primera postura adolece de "una confusión entre lo correcto y lo ejemplar", mientras que los partidarios de la segunda "aunque reconocen que hay algo que puede llamarse correcto, piensan que lo correcto no tiene ninguna importancia" (págs. 23-24). Ambas posturas son contrarias, pero no contradictorias; y, en su voluntad de deslindar corrección de ejemplaridad, clasifica en dos tipos las confusiones en que caen hablantes y lingüistas: confusiones en sentido vertical, cuando se juzga como correcto algo que no es susceptible de serlo, y confusiones en sentido horizontal, cuando subsumimos lo correcto en lo ejemplar y viceversa. Grosso modo, Coseriu defiende una especialización terminológica entre corrección, como aquello que compete a la norma o posibilidades de un sistema lingüístico (estén bien valoradas socialmente o no); y ejemplaridad, como modo de hablar basado en la corrección, pero constitutivo de la tradición discursiva que una comunidad adopta para determinadas funciones culturales de rango superior (la literatura, la ciencia, la política, etc.).

Este deslindamiento entre corrección (norma de la lengua realmente existente) y ejemplaridad (norma de la lengua sociológicamente estipulada) se fundamenta, en el segundo capítulo, con una recensión de las principales ideas de la teoría general del hablar de Coseriu. Se sigue, pues, la ya clásica tripartición en niveles o planos lingüísticos. El nivel universal compete al saber hablar en general. Como todos los saberes lingüísticos, este saber no es un saber científico, sino una técnica intuitiva -téchne- denominada saber elocucional; esto es, "saber hablar de acuerdo a ciertos principios universales del pensar" (pág. 33). En el plano histórico, por su parte, se da el denominado saber idiomático o "saber hablar de acuerdo con la tradición lingüística de tal comunidad" (pág. 33). En el plano individual, por último, se da el saber expresivo o "saber correspondiente al estructurar discursos" (pág. 34). El producto del saber elocutivo es aquello que llamamos lenguaje; y, el del saber expresivo, texto. Así, lo que entendemos como lengua tiene que ver únicamente con el saber idiomático del plano histórico (lengua española, lengua italiana, lengua alemana...). Coseriu centra el problema de la corrección en el nivel histórico, para 
lo cual añade una tripartición de los juicios pertinentes en cada plano, "la serie de juicios que aprecian el hablar en relación con el saber lingüístico" (pág. 60). Si el saber elocucional se juzga como congruente o incongruente y el expresivo, como apropiado o inapropiado; es el saber idiomático el que se ha de juzgar como correcto o incorrecto. De este modo, Coseriu ciñe la noción de corrección a la lengua, es decir, a una tradición idiomática sincrónicamente funcional en una comunidad de hablantes.

El capítulo tercero cierra el bloque de contenidos más abstracto y abre el siguiente con un problema concreto: el problema de la corrección en Hispanoamérica. Al hilo de la corrección como un concepto estrictamente concerniente al saber idiomático, advierte Coseriu que "los llamados criterios de corrección [...] son no criterios de corrección, sino ideales o modelos de corrección" (pág. 67); esto es, toda una tradición de directrices para el reconocimiento de un modo de hablar como ejemplar. Luego, los llamados criterios de corrección -criterios geográficos, demográficos, literarios...- no serían tales y, aun cuando lo fueran, tampoco podrían aplicarse, pues son todos ellos criterios extralingüísticos. A lo sumo, nuestro autor salva el criterio del uso, si bien críticamente, ya que este criterio se aplica tanto a la corrección, como a lo elocucional y lo expresivo. ¿Cuál es, entonces, el lugar de ese saber también tradicional que es la ejemplaridad? Sin duda, está contenido en el saber idiomático. Ahora bien, la lengua es, además de un sistema, un conjunto de tradiciones, "una colección compleja de dialectos, niveles y estilos de lengua" (pág. 74). Las diferencias entre, p. ej., la lengua funcional de un rioplatense de clase alta en un contexto familiar y la de un valenciano de clase baja en un contexto laboral son palmarias, pero no insalvables. Así, haciendo uso de los conceptos de estructura, arquitectura y diasistema, el autor define la lengua ejemplar como "lengua común de la lengua común, por lo menos para aquellas tareas [...] que representan a la cultura mayor de esta comunidad" (pág. 76). Con esta definición de la lengua ejemplar, Coseriu procede con la demolición de algunos mitos, como la centralidad peninsular de nuestro idioma, las simplificaciones en torno a la denominación español/castellano, la dificultad de crear un estándar supradialectal, la inmutabilidad de este estándar o la ilusión de que todas las lenguas históricas son iguales, solo porque cualquier sistema es potencialmente idéntico a otro.

Si el tercer capítulo ejemplifica algunos problemas prácticos fruto de la confusión entre lo correcto en calidad de norma idiomática y lo correcto en calidad de ejemplar, el capítulo cuarto analiza las principales características por las que juzgamos un modo de hablar como correcto, al tiempo que introduce las posibilidades expresivas de suspender estos juicios de corrección. En lo tocante a estos "caracteres de lo correcto, en particular, con respecto a la ejemplaridad", Coseriu enumera seis propiedades necesarias. Primero, la corrección está siempre en línea con una tradición: el saber idiomático presenta diferentes normas que varían en el tiempo, se mantienen en algunos ámbitos y en otros no, en unos ámbitos son ejemplarizantes, en otros pedantes, etc. Ahora bien, lo correcto, en segundo lugar, es siempre actual. Intencionalmente, un hablante puede ser más o menos arcaizante en su modelo de ejemplaridad, pero idiomáticamente solo puede valerse de aquellos recursos del sistema que de facto funcionan en sincronía. Esto es así porque, en tercer lugar, la corrección es siempre histórica; es decir, no puede ajustarse -por mucho que se intentea decisiones arbitrarias de académicos o políticos, quienes "en el mismo momento en que 
sostienen que constituirán lo correcto [...] advierten que se trata de lo incorrecto" (pág. 91). En cuarto lugar, la corrección es dinámica: los hablantes pueden producir innovaciones bien formadas de acuerdo con el sistema, pero estas innovaciones serán norma si y solo si no entran en conflicto con otra norma ya existente (la cual podrá o no adquirir el rango de ejemplar frente a la nueva). Quinto, la corrección es objetiva o, al menos, objetivable, pues puede delimitarse a partir de las incorrecciones, siempre más numerosas ("para cada norma debe haber por lo menos dos posibilidades de desviación"; pág. 96). Sexto y último, la corrección es intersubjetiva: la objetivación de la corrección depende enteramente de que un grupo, si no total, mayoritario de hablantes convenga en qué es correcto y qué no. Esta última propiedad, la intersubjetividad, redunda en el fenómeno de la suspensión de los juicios de corrección; es decir, cuando se dice algo incorrecto, "los mismos hechos pueden considerarse como errores o como no errores empleados en diferentes niveles" (pág. 99). Tal es el caso de las desviaciones estilísticas, expresiones deliberadamente marcadas, modos de hablar, simplificación de las reglas idiomáticas cuando se habla con extranjeros que no dominan nuestra lengua, etc.; diferentes tipos de suspensión que el autor clasifica como suspensiones bien genéricas, bien específicas.

Habiendo -hasta este punto- problematizado el concepto de corrección, aplicado su teoría general del hablar a la corrección en el mundo hispano y desgranado los caracteres de los correcto y lo ejemplar, la obra concluye con una reflexión sobre la importancia de estos dos conceptos en la educación lingüística. La defensa que hace Coseriu de la educación lingüística, a partir de la cual los hablantes pueden acceder a la cultura de rango superior, pasa por una reivindicación de esa tradición común que es la norma ejemplarizante. Sin embargo, la utilidad de la corrección en la enseñanza no se limita a la mera adquisición de un nivel de lengua culto (como una suerte de carta de presentación elegante), sino que la ejemplaridad es solo el punto de partida para otras cuatro metas. Primero, frente a ciertas opiniones más o menos biempensantes por la que "los alumnos saben la lengua y que, por lo tanto, no hay que enseñársela" (pág. 106), es fundamental ahondar en ese saber idiomático para, en segundo término, fomentar la capacidad metalingüística de los estudiantes mediante la enseñanza de la gramática. En tercer lugar, la educación lingüística ha de contemplar también el saber expresivo y -a juicio del autor, lo más apremiante- el elocucional; de ahí que, en cuarto lugar, sea conveniente una metodología conceptualmente sólida (en una palabra, "[q]uien no sabe de las cosas, habla de los métodos"; pág. 114).

En definitiva, cada capítulo ofrece una serie de herramientas que, lejos de agotarse en la teoría, identifican y explican hechos lingüísticos de la realidad; algo que, de manera dialéctica, se complementa a lo largo de todo el texto con la transcripción de las intervenciones de los asistentes al curso original, génesis de esta lectura indispensable para maestros e investigadores. 